\title{
Delineation of Suitable Areas for Maize in China and Evaluation of Application for the Technique of Whole Plastic-Film Mulching on Double Ridges
}

\author{
Chaojie Jia, Wenlong Zhao, Yaxiong Chen, and Guojun Sun \\ MOE Key Laboratory of Arid and Grassland Ecology, Lanzhou University, \\ Lanzhou, Gansu Province, 730000, P.R. China \\ jiachaoj280@126.com
}

\begin{abstract}
Climate, topography, soil and land use data which closely associated with the distribution of maize (Zea mays L.) has been collected and collated to identify the suitable areas for maize on condition of nature and using the technique of whole plastic-film Mulching on Double Ridges in China, the database of these factors have been created in the current article. The weights of these factors, criteria and suitability levels have been defined using Multi-Criteria Evaluation (MCE) approach based on Geographic Information System (GIS), each factor was classed into five suitability levels: Most suitability, Moderate suitability, and medium, Moderate unsuitability and Unsuitability. Pair-wise comparison matrixes were made to get the weights of each factor, the suitability maps of the factors have been obtained by overlaying these layers according to their weights, got the suitability map for maize. The suitable areas map was created by the suitability map and the land use map which has been masked the non-cultivated land. The result indicated that the higher yield of maize can be gained from $4.535 \times 10^{5} \mathrm{~km}^{2}$ which distributed in 741 counties in 16 provinces. In accordance with the method of above, analysis the suitable area after the techniques of whole plastic-film mulching on double ridges was used. The results showed the higher yield could be got in $6.145 \times 10^{5} \mathrm{~km}^{2}$, some areas of Gansu, Inner Mongolia and other places in arid and semiarid areas that can't distribute or only have low yield maize could get higher yield after using the technique of whole plastic-film mulching on double ridges. With the increased requirement of food, the new techniques and the more perfect regional planning of grain could be take into account for socio-political and environment issues.
\end{abstract}

Keywords: Multi-Criteria Evaluation (MCE), Spatial analysis, whole plastic-film mulching on double ridges, Geographic information system (GIS).

\section{Introduction}

Protected cultivation, mainly represented by plastic-film mulching, has greatly improved crop production worldwide since the 1950s [1]. However, the technique of whole plastic-film mulching on double ridges is trialed in China from the 1990s, and is in phase of field test and promotion currently. The technique can reduce water loss through evaporation, therefore may increase water available to plants, and increase

D. Li, Y. Liu, and Y. Chen (Eds.): CCTA 2010, Part I, IFIP AICT 344, pp. 3904400, 2011.

(C) IFIP International Federation for Information Processing 2011 
the topsoil temperature [2]. It could be applied in the areas that have low temperature or rainfall to improve the grain yield.

To research and develop agriculture on condition of using the technique of whole plastic-film mulching on double ridges, the accurate identification and the characterization of current production areas and potential areas are necessary [3]. MCE approach was used to determine relevant criteria (factors) which is understanding as the biophysical restraints and defined the suitability levels for each factors. MCE was defined as "an umbrella term to describe a collection of formal approaches which seek to take explicit account of multiple criteria in helping individuals or groups explore decisions that matter [4], could be understood as a world of concepts, approaches, models and methods that aid an evaluation (expressed by weights, values or intensities of preference) according to several criteria [5]. MCE has been one of the most widely applied models in management and planning because of it was (1) the formal approach, (2) the presence of multiple criteria and (3)the evaluation are made either by individuals or groups [6]. Geographic information system (GIS) has a powerful function in spatial analyses such as: predicting the distribution of the wild relatives of bean by analyzing climate conditions that favor bean's growth, and for planning potential conservation areas by using relationships between environmental factors and the distribution of birds. However, the utility or GIS functionality in the management of the above areas has been limited by the restrictions inherent in overlaying of digital information maps. Some of these restrictions are: (1) overlays are difficult to use when there are many underlying variables (more than 4), (2) the overlay procedure does not enable one to take into account that the underlying variables are not of equal importance [7]. From the 1990s, integration of the MCE approach with GIS for solving spatial planning problems has received considerable attentions among urban planners. The ability of GIS to integrate with the MCE approach has been shown in studies related to site determination for a nuclear waste facility and for a noxious waste facility. And the GIS-based MCE has also extended to solving planning problems that involve conflicting multi-objectives such as land use allocation problems[78] MCE seems to be applicable to GIS-based land suitability analysis[9] and help us to carry out the delineation of suitable areas for crops. The maize is one of the most important grain and forage crops in China, playing a crucial role in protect food security. The main goal of this research is to describe suitable areas for maize on condition of natural and after use the technique of whole plastic-film mulching on double ridges under the GIS based MCE to evaluate the application area for the technique of whole plastic-film mulching on double ridges. With the increased requirement of food, the new techniques and the more perfect regional planning of grain could be take into account for socio-political and environment issues.

\section{Methods}

\subsection{Study Areas}

The study area throughout the land of China, include mainland of China, Hong Kong Special Administrative Region, the Macao Special Administrative Region and Taiwan province. It is located latitude from $3^{\circ} 52^{\prime} \mathrm{N}$ to $53^{\circ} 33^{\prime} \mathrm{N}$ and longitude from $73^{\circ} 40^{\prime} \mathrm{E}$ to $135^{\circ} 2^{\prime} 30^{\prime \prime} \mathrm{E}$. The total area is approximately $9600000 \mathrm{~km}^{2}$. 


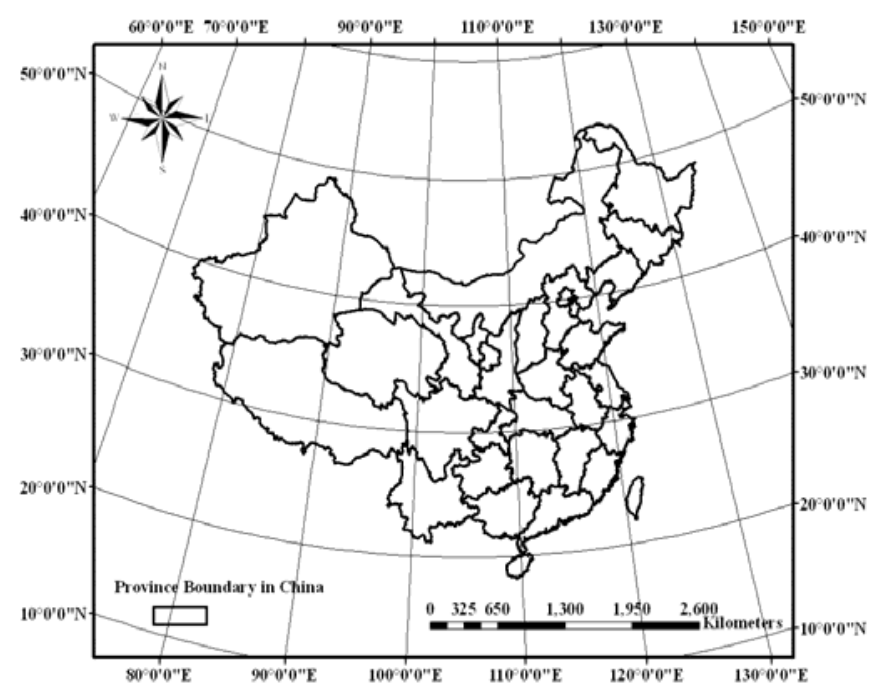

Fig. 1. The study areas

\subsection{Procedures}

The distribution and growth of crops are decided by water, temperature, light and soil. According to the: leading dominant (the main factor affecting the growth of maize); incompatibility (the factor affect the maize independence); diversity (selected factors were significantly different, can express the threshold); marketability (factors which be chosen have a corresponding data)[10] In the light of expert opinions, as well as literature, eight factors which are closely connected with the growth of maize were selected to establish the relevant criteria of MCE. They were: accumulated temperature, average temperature in April which was regarded as the Minimum temperature, the average temperature in July was the Maximum temperature, the annual precipitation, Soil Texture, Soil pH, Elevation and Field water-holding capacity. Then, the database was established.

\subsubsection{Establish of Spatial Databases}

\section{Climate Database}

Climate information was obtained from 722 meteorological stations which belong to the China Meteorological Administration and located within or close to the study area. The recorded years were from 1978 to 2008. The format of original data which we obtained was text, calculated in the EXCEL; Based on these data, Accumulated temperature $\left(\geq 10{ }^{\circ} \mathrm{C}\right)$, the Minimum temperature, the Maximum temperature and the Precipitation was extracted and calculated separately. Convert the data to point in ArcGIS, and then interpolate the temperature data and the precipitation data with the Kriging and the IDW method. Before interpolation for the spatial data, compare the accuracy of various interpolation are necessary. $90 \%$ of the points were used as the 


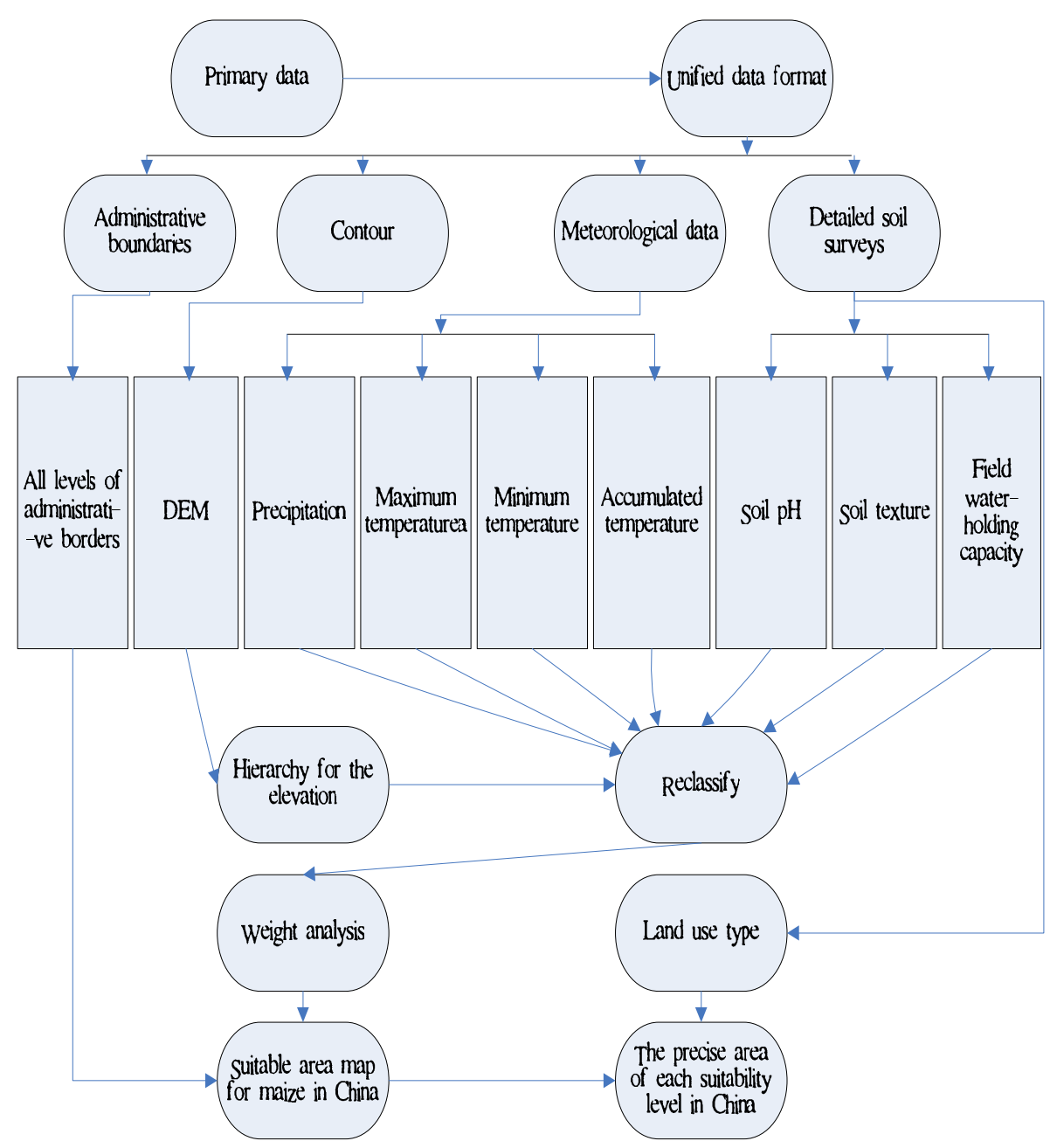

Fig. 2. The flow chart shows the main procedures applied in this study

training points and the other were test points, using mean relative error (MRE) between the measured (Zoi) and the value after interpolation to test the accuracy of the inverse distance weighting (IDW), ordinary kriging(OK), spline(SP) and trend surface (TR). Formula as follows:

$$
M R E=\frac{1}{n} \sum_{i=1}^{n}\left|\frac{Z_{o i}-Z_{e i}}{Z_{o i}}\right|
$$


Table 1. The compare of accuracy of various interpolation method

\begin{tabular}{lll|l|lc}
\hline & IDW & OK & SP & \multicolumn{1}{l}{ TR } & \\
\cline { 2 - 6 } accumulated temperature & 0.137713 & 0.082544 & 0.159480 & 0.098259 \\
Minimum temperature, & 0.105527 & 0.096969 & 0.115875 & 0.134711 \\
Maximum temperature & 0.098793 & & 0.055474 & 0.088144 & 0.092951 \\
\hline
\end{tabular}

The results showed that $\mathrm{OK}$ was the best interpolation for the temperature.

\section{Soil Database}

Soil characteristics data were taken from digital Soil Type Maps (from ISSCAS) using a scale of 1:1 000 000. Sampling points was created, the total number of points were 99034. The information of soil texture and soil $\mathrm{pH}$ was obtained from soil type. Then the soil texture point data and the soil $\mathrm{pH}$ point data were interpolated into grid maps within ArcGIS.

\section{Relief Database}

The altitude data were obtained from the digital elevation model (DEM). DEM has characteristics of space location and attribute of terrain, it is an indispensability part when establish resource and environment information in different levels. National digital contour map at the scale of 1:250,000was obtained from the State Bureau of Surveying and Mapping. This contour data was used to create DEM within ArcGIS, the process was contours $\rightarrow$ TIN $\rightarrow$ lattice $\rightarrow$ DEM.

\section{Unification of the data format}

All the data was converted to the same format, the spatial resolution was $1000 \mathrm{~m}$ per pixel, the Krasovsky_1940_Albers coordinate system was used as the projected coordinate system and GCS_Krasovsky_1940 was the geographic coordinate system. The spheroid of the maps was the Krasovsky_1940 and the datum was D_Krasovsky_1940.

\subsubsection{MCE Process for Suitable Areas of Maize}

\section{Define specific suitability level of the factors}

By means of expert opinion and literatures, a specific suitability level per factor for maize on condition of natural and using the whole plastic-film mulching on double ridges technical was defined (Table 2). These levels were used as a base to construct the criteria maps. The levels were: Most suitable, Moderate suitable, Medium, Moderate unsuitable, unsuitable. Then factor maps were constructed in the ArcGIS environment. On condition of using the technique of whole plastic-film mulching on double ridges the threshold of restriction of precipitation was decreased for $50 \mathrm{~mm}$ [11], and the accumulated temperature restriction decreased for $650^{\circ} \mathrm{C}[12]$, the restriction condition of Min temperature decreased $2^{\circ} \mathrm{C}$ and elevation reduced for $300 \mathrm{~m}$, the field water-holding capacity decreased for $0.10[13]$. 
Table 2. Level of suitability for maize on condition of nature

\begin{tabular}{|c|c|c|c|c|c|}
\hline \multirow[b]{2}{*}{ Factor } & \multicolumn{5}{|c|}{ Level of suitability on condition of nature } \\
\hline & Most suitable & Moderate suitable & Medium & $\begin{array}{l}\text { Moderate } \\
\text { unsuitable }\end{array}$ & Unsuitable \\
\hline $\begin{array}{l}\text { Accumulated } \\
\text { temperature }\left(\geqslant 10^{\circ} \mathrm{C}\right)\left({ }^{\circ} \mathrm{C}\right)\end{array}$ & $2500-3300$ & $3300-5000$ & $5000-7000$ & $1000-2500$ & $<1000$ or $>7000$ \\
\hline Precipitation (mm) & $500-800$ & $300-500$ or $800-1500$ & $500-2000$ & $>2500$ & $0-300$ \\
\hline $\begin{array}{l}\text { Maximum temperature } \\
\left({ }^{\circ} \mathrm{C}\right)\end{array}$ & $20-25$ & $15-20$ or $25-30$ & $5-15$ & $>25$ & $<5$ \\
\hline Soil texture & Loam & Sandy loam & Sand clay loam & Other class & Sand or clay \\
\hline Soil PH & $6.5-7.0$ & $5.0-6.5$ & $7.0-8.0$ & $<5.0$ & $>8.0$ \\
\hline Elevation $(\mathrm{m})$ & $<1200$ & $1200-1500$ & $500-3000$ & $300-3600$ & $>3600$ \\
\hline $\begin{array}{l}\text { Field water-holding } \\
\text { capacity }(\%)\end{array}$ & $0.30-0.46$ & $0.25-0.30$ & $0.23-0.25$ or $0.46-0.50$ & $0.18-0.23$ & $<0.18$ or $>0.50$ \\
\hline
\end{tabular}

Table 3. Level of suitability for maize on condition of using the Technique of Whole Plastic-Film Mulching on Double Ridges

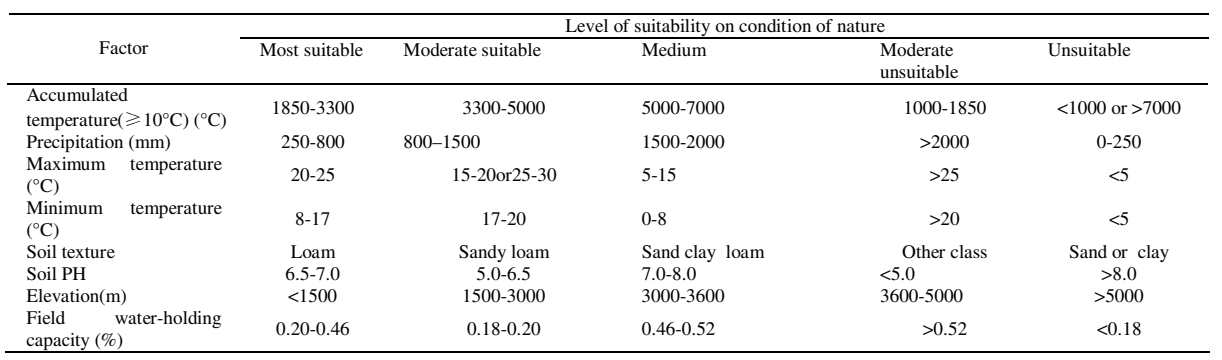

\section{Weighting for the factors}

A variety of techniques exist for the development of weights, but the promising technique is the pair wise comparison developed by Saaty (1977) in the context of a decision-making Process known as the Analytical Hierarchy Process (Eastman et al., 1995). It has characterized of systematization, flexibility and practicality. Relative importance of each factor were compared, according to regression between them and final yield of maize, the score of each factor were given, and amend the score with the relationship between them. The first pair-wise comparison matrix was obtained. Ratings were provided on a nine-point continuous scale, which ranges from 9 to $1 / 9$. A 9 indicates that relative to the column variable, the row variable is significantly more important. A $1 / 9$ indicates that relative to the column variable, the row variable is significantly less important. Statistic the number of each factor appeared in the literature which described the yield and the distribution of maize, establish another Pairwise comparison matrixes. Test two matrix use the CRJ (Matrix Consistency ratio), if the $\mathrm{CRJ}<0.10$ matrix was available; if the $\mathrm{CRJ}>0.10[14]$, we must amend the matrix on the opinion of experts who research the maize. Weight was calculated in the MATLAB software using the pair-wise comparison matrixes above.

\subsubsection{Mask}

Overlay the factor maps with their weight, and then crossing the land use/cover map which has been taken out of the city, lakes, rivers and other types of land that can't or won't grow the crops with the suitability map to find the plant areas. These works were conducted with the Weighted Overlay Module in the ArcGIS environment. 
Table 4. Analysis of weight for various factors

\begin{tabular}{cccccccccc}
\hline Factor & $\begin{array}{c}\text { accumulated } \\
\text { temperature }\end{array}$ & Precipitation & $\begin{array}{c}\text { Minimum } \\
\text { temperature }\end{array}$ & $\begin{array}{c}\text { Maximum } \\
\text { temperature }\end{array}$ & $\begin{array}{c}\text { Field water- } \\
\text { holding } \\
\text { capacity }\end{array}$ & $\begin{array}{c}\text { Soil } \\
\text { texture }\end{array}$ & Soil pH & Elevation & $\begin{array}{c}\text { Total } \\
\text { weight }\end{array}$ \\
\hline \multirow{2}{*}{ Weight } & 0.209348 & 0.19134 & 0.141142 & 0.163879 & 0.11368 & 0.075808 & 0.059333 & 0.04547 & 1 \\
\hline
\end{tabular}

\section{Results}

The technical play a marginal role when maize in the stage of milky(Zhao F. 2005). The most suitable area of six factor maps was extent after use the technical, especially the Precipitation was the most significant. It means that this technical has a prominent role for the Precipitation. The area that distensible mainly distributed in where the arid and semiarid area or the cold area. The Field water-holding capacity also has the significant change.

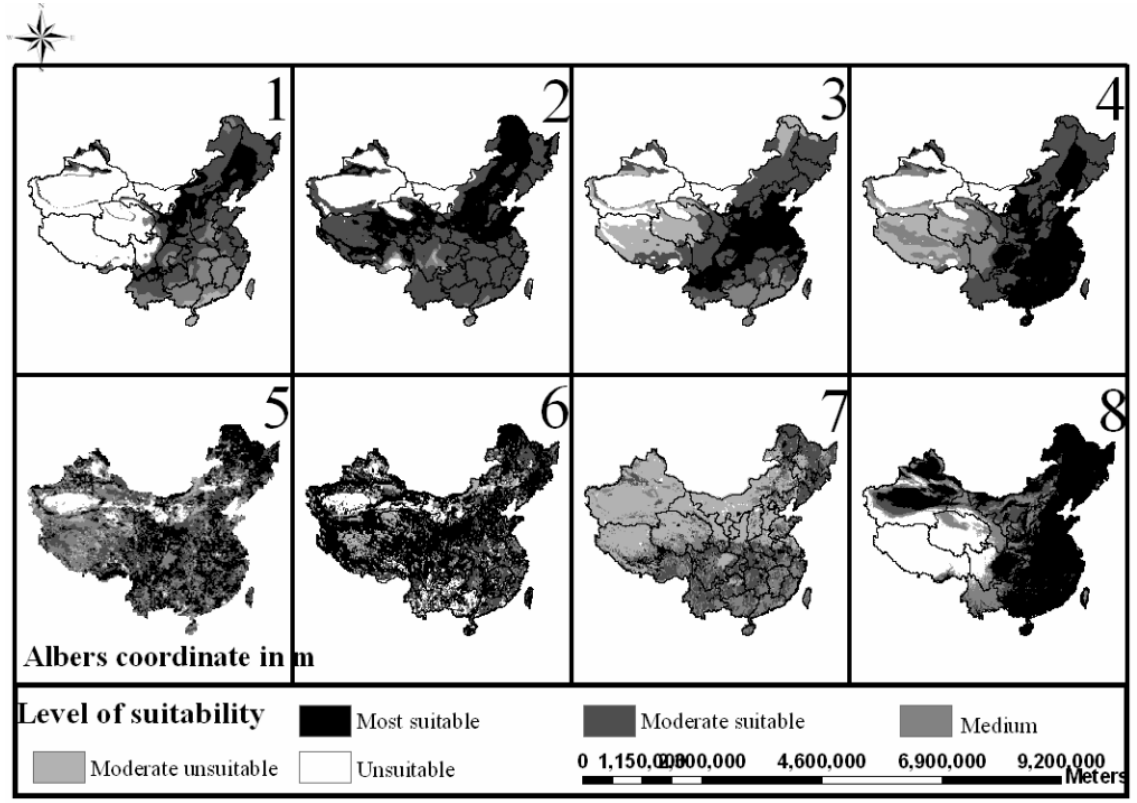

Fig. 3. Factor maps for maize on condition of natural, including suitability levels for each factor. $1=$ Accumulated temperature, $2=$ Precipitation, $3=$ Minimum temperature, $4=$ Maximum temperature $5=$ Field water-holding capacity, $6=$ Soil texture, $7=$ Soil $\mathrm{pH}, 8=$ Elevation.

On condition of natural, the area of the most suitable level was $4.53505 \times 105 \mathrm{~km} 2$, the moderate suitable level was $2.048032 \times 105 \mathrm{~km} 2$. After using the whole plastic-film mulching on double ridges technical, the area of the most suitable level was $6.14456 \times 105$ $\mathrm{km} 2$ and the moderate suitable level was $2.12719 \times 105 \mathrm{~km} 2$. The most and moderate suitable level could got more yield and was considered use the land efficiently. 


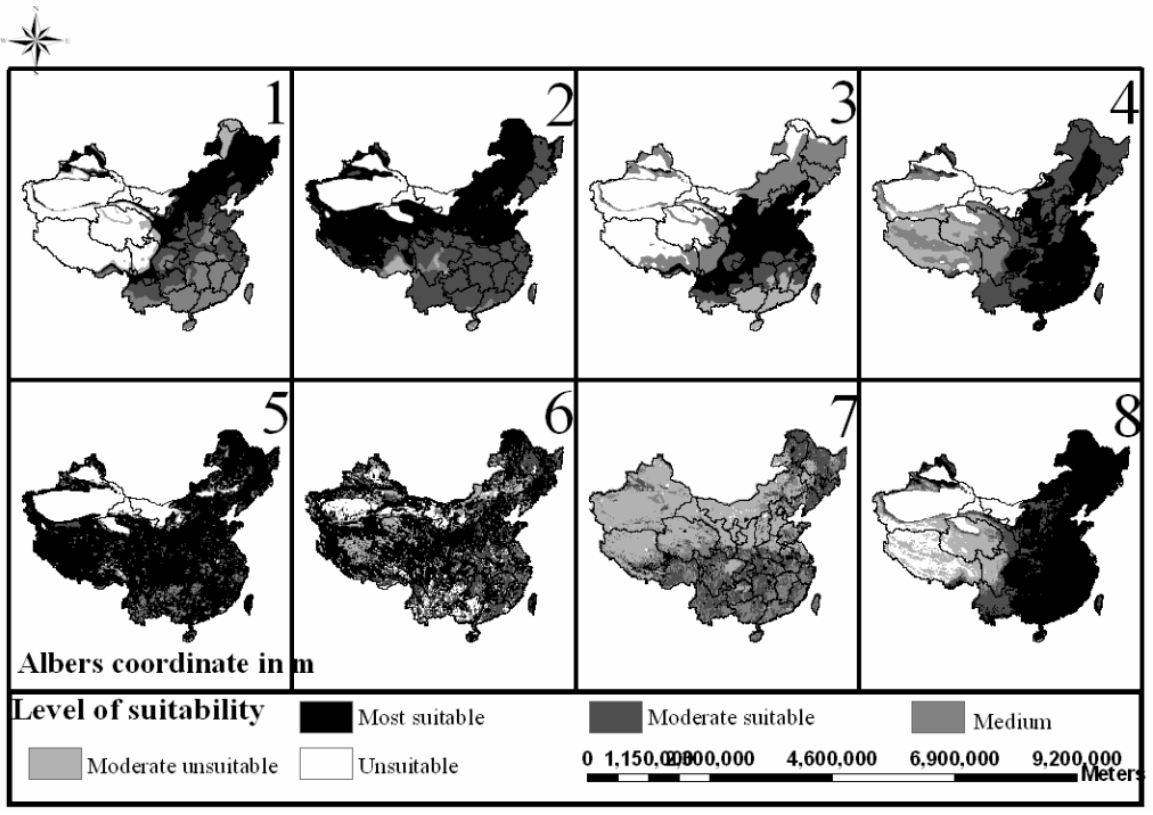

Fig. 4. Factor maps for maize on condition of using the whole plastic-film mulching on double ridges technical, including suitability levels for each factor. $1=$ Accumulated temperature, $2=$ Precipitation, 3=Minimum temperature, $4=$ Maximum temperature 5= Field water-holding capacity, $6=$ Soil texture, $7=$ Soil $\mathrm{pH}, 8=$ Elevation.

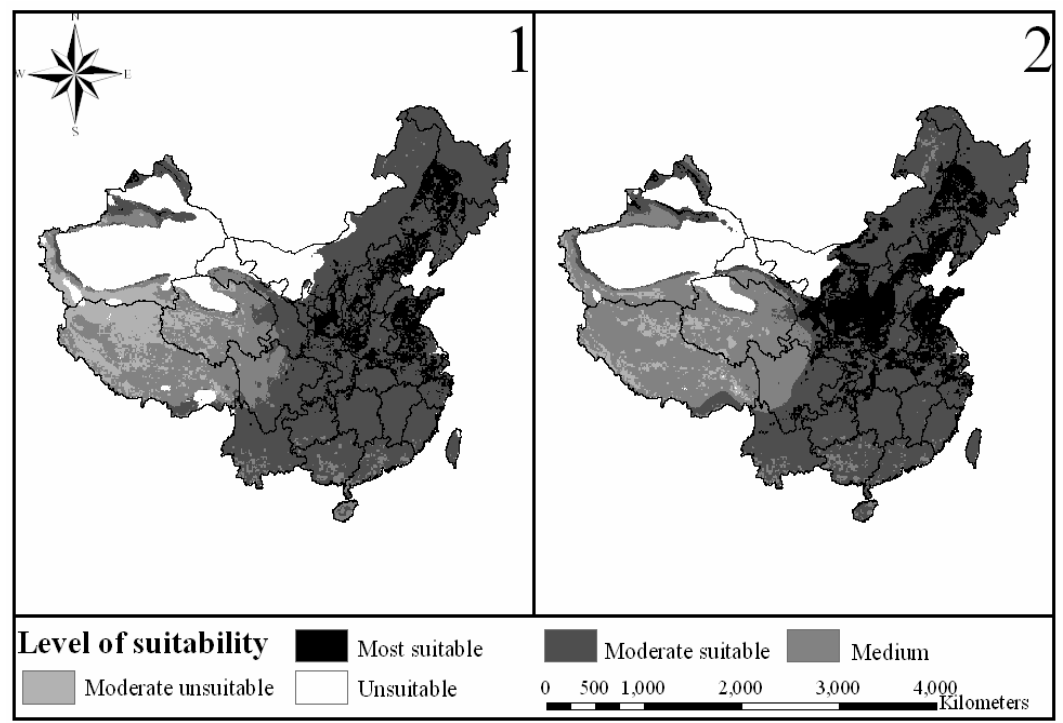

Fig. 5. Maps of suitability for maize in China (1) On condition of nature (2) on condition of using the whole plastic-film mulching on double ridges technical 


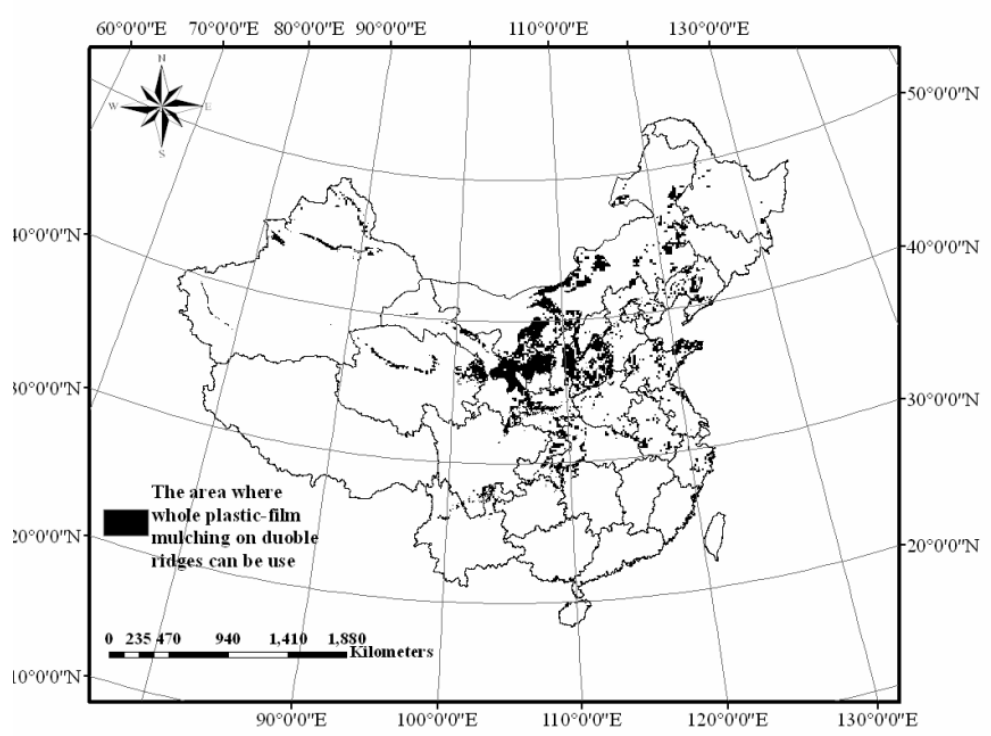

Fig. 6. The map of the area congruent for using the whole plastic-film mulching on double ridges

Evaluate the suitable level use the same method and then crossing the land use/cover map, the result showed that there are $1.609 \times 105 \mathrm{~km} 2$ increased from the other levels to the most suitable levels, that lead the yield of maize increased about $6.29 \times 1010 \mathrm{~kg}$. $7.97 \times 104 \mathrm{~km} 2$ of the other levers was improved to the moderate suitable level, and that bring on the yield of maize increased about $1.642 \times 1010 \mathrm{~kg}$. The area that congruent for using the whole plastic-film mulching on double ridges was located in Inner Mongolia, Gansu, Ningxia, Shanaxi, Shanxi and so on. The precipitation of these province was the restrict condition for developing agriculture. In other areas which could use the technical were mainly because it could improve the temperature of topsoil.

\section{Discussion}

Production and distribution of maize was the result of multi-factor effect [15], the eight factors which have been chosen in this research were the restrictive factor in various stage of maize growth in the natural conditions. Based on the report of Ceballos-Silva et al, the spatial data input, extraction, analysis and visualization functions of GIS were used to establish the national spatial database of climate, topography and soil. MCE procedure in this research was useful to evaluate the suitable areas for maize. As the first phase of MCE, the factors were selected based on agronomic knowledge of local experts and reviews of existing literature. And then the Pair-wise comparison matrixes in the context of Analytical Hierarchy Process were made to obtain the weights and confirmed to be a useful approach. Finally, five suitability levels of maize were divided using the method of GIS-based MCE crossing this the 
land use/cover map, calculate the plow land of every levels. After use the technique of whole plastic-film mulching on double ridges, the threshold of some natural condition for restriction of maize decreased and that lead to the areas were extent.

The GIS based MCE allowed us use more database of spatial to evaluation the suitable levels of maize as different significance. The weights was obtained in this paper can be used in many similar research of maize. The feedback process of checking the results by local agronomic experts was involved, and results could be adjusted in light of their experience.

The results of evaluation for natural condition showed that this method was reliable and reasonable. Expert system based on the research results will be constructed and connected with the internet to facilitate the work of decision-makers and farmers.

However, the identified variety-suitable areas were proposed at a theoretical maximum, the microclimate and micro topography of the specific areas should be considered in the actual production. Decision-making process to select adequate crop patterns could be based on other issues such as: production supports (by local and federal governments), marketing, technological level, economic evaluation, in addition to local cultural traditions, which are very important also. This factor could be used in the further research.

\section{Conclusion}

In this research, the MCE approach was applied to identify the suitable level and area for maize in the condition of natural and use the technique of whole plastic-film mulching on double ridges within GIS environment. The results confirmed that the methodology used was adequate to construct and integrate spatial databases of climate, soil, topography and land use. The interpolated factor maps of temperature, precipitation, elevation, soil $\mathrm{pH}$, soil texture class and land use information were crucial in identification of suitable areas for maize. The technique was more useful for the arid and semiarid area to increase the yield of grain, especially for the north-west of China. Crop mapping based on the results will be constructed and connected with the internet which facing the government and farmers to adjust agricultural structure according to market conditions.

\section{Acknowledgments}

This work is financial supported by the ISTCP for Construction of an Information Platform/module in Eco-agricultural Assessment and Management (EAM) (2010DFA31450) and National Science Fund for Talent Training in Basic Science (J0630644).

\section{References}

1. Anikwe, M.A.N., Mbah, C.N., Ezeaku, P.I., Onyia, V.N.: Tillage and plastic mulch effects on soil properties and growth and yield of cocoyam (Colocasia esculenta) on an ultisol in southeastern Nigeria. Soil\&Tillage Research 93, 264-272 (2007) 
2. Li, L.X., Liu, G.C., Yang, Q.F., Zhao, X.W., Zhu, Y.Y.: Different conservation tillage related with soil water. Soil Temperature and Yield of Potato in Rainfed Farming System. Agricultural Research in the Arid Areas 27(1), 114-118 (2009) (in Chinese)

3. Corbett, J.H.: Dynamic crop environment classification using interpolated climate surfaces, GIS and Environmental Modeling: Progress Research Issues. Wiley, New York (1996)

4. Belton, S., Stewart, T.S.: Multiple Criteria Decision Analysis. An Integrated Approach. Kluwer Academic Publishers, Massachusetts (2002)

5. Barredo. C.J.I. Systems Information Geography evaluation multi-criterion ordination delterritorio. Editorial RA-MA Editorial, Madrid, Espana (1996)

6. Mendoza, G.A., Prabhu, R.: Combining participatory modelling and multi-criteria analysis for community-based forest management. Forest Ecol. Manage. 207, 145-156 (2005)

7. Janssen, R., Rietved, P.: Multicriteria analysis and GIS: an application to agriculture landuse in the Netherlands. In: Scholten, H., Stilwell, J. (eds.) Geographical Information Systems for Urban and Regional Planning. Kluwer, Dordrecht (1990)

8. Eastman, J.R., Jin, W., Kyem, A.K., Toledano, J.: Raster procedures for multicriteria/multiobjective decisions. Photogrammetric Engineering and Remote Sensing 61(5), 539-547 (1995)

9. Pereira, J.M.C., Duckstein, L.: A multiple criteria decision-making approach to GIS-based land suitability evaluation. International Journal of Geographical Information Science 7(5), 407-424 (1993)

10. Shi, B.S., Wen, Z.P.: The weighted method for the score that experts give. China Academic Journal Electronic Publishing House (5), 57-58 (1996)

11. Zhao, F.: Analysis of gray association between soil water with rainfall under the full coverage double-ridge with plastic and water utilization rate for maize. Agricultural Research in the Arid Areas 27(1), 89-94 (2009)

12. Zhao, F.: The advantage and The application of the technique of whole plastic-film mulching on double ridges. Tillage \& Cultivation (6), 62-63 (2005)

13. Ma, Z.M.: The research for the water-saving technology of the whole plastic-film mulching on double ridges for maize. Gansu Agricultural Science and Technology (2), 27-29 (1999)

14. Yuan, H.Y., Zhang, X.Y., Kang, Y.L., Hou, B.X.: The climate factor and the maize field in NingXia irrigation zones. Ninxia Journal of Agriculture and Forestry Science and Technology (4), 24-27 (2007) (in Chinese)

15. Li, Y.Z., Dong, X.W., Liu, G.L., Tao, F.: Light and temperature on maize yield components of value. Agricultural Ecology 10(2), 86-89 (2002) (in Chinese) 